\title{
openheart Predictors and outcomes of early coronary angiography in patients with prior coronary artery bypass surgery presenting with non-ST elevation myocardial infarction
}

\author{
Muhammad Asrar ul Haq, ${ }^{1,2}$ Nima Rudd, ${ }^{1,2}$ Mueed Mian, ${ }^{1}$ Anastasia Castles, ${ }^{1}$ \\ Tamara Mogilevski, ${ }^{1}$ Vivek Mutha, ${ }^{1,2}$ William J Van Gaal ${ }^{1,2}$
}

To cite: Asrar ul Haq M, Rudd N, Mian M, et al. Predictors and outcomes of early coronary angiography in patients with prior coronary artery bypass surgery presenting with non-ST elevation myocardial infarction. Open Heart 2014;: :e00059. doi:10.1136/openhrt-2014000059

Received 17 February 2014 Revised 6 May 2014 Accepted 28 May 2014

CrossMark

${ }^{1}$ Department of Cardiology, The Northern Hospital, Melbourne, Victoria, Australia ${ }^{2}$ Department of Medicine, University of Melbourne, Melbourne, Victoria, Australia

\section{Correspondence to}

Dr Muhammad Asrar ul Haq muhammad.asrar@unimelb. edu.au

\section{ABSTRACT}

Introduction: The best strategy in patients with prior coronary artery bypass graft surgery (CABG) who present with non-ST elevation myocardial infarction (NSTEMI) remains less well defined. We compare the characteristics, therapeutic interventions and outcomes of patients with prior CABG presenting with NSTEMI.

Methods: All patients who presented to our hospital during 2007-2012 with available electronic records were analysed retrospectively. Outcomes were compared between patients who underwent coronary angiography or percutaneous coronary intervention $(\mathrm{PCl})$ versus those who were treated medically.

Results: A total of 117 patients were analysed. Of that, 79 patients were managed medically while 38 underwent early angiography, of which only 11 (9.5\%) received $\mathrm{PCI}$. Patients treated medically (did not undergo angiography) were older ( $74 \pm 10$ vs $70 \pm 8$; $p=0.05)$. ECG changes were the only independent predictor for early angiography (OR $0.4,95 \% \mathrm{Cl} 0.15$ to $0.99 ; p=0.05$ ) while recurrent chest pain (OR $0.2,95 \%$ $\mathrm{Cl} 0.05$ to $0.97 ; \mathrm{p}=0.05$ ) predicted $\mathrm{PCl}$ on multivariate analysis. The $\mathrm{PCl}$ group had higher Global Registry of Acute Cardiac Events (GRACE) score ( $176 \pm 29$ vs 150 $\pm 31 ; p=0.01$ ). No significant difference was found in readmission rates, morbidity (unstable angina pectoris, NSTEMI, ST elevation myocardial infarction (STEMI), or combination) or mortality at 12 months between the groups who underwent angiography, $\mathrm{PCl}$, or treated medically on univariate and multivariate analysis.

Conclusions: The opportunity to intervene in prior CABG patients presenting with NSTEMI is often low. Initial medical management may be a reasonable option in carefully selected patients particularly in the absence of ongoing symptoms, ECG changes or very high GRACE scores. Further studies are required to evaluate the safety of non-invasive strategies in managing this population.

\section{INTRODUCTION}

Coronary artery disease (CAD) is a major healthcare challenge worldwide. Despite the

\section{KEY MESSAGES}

Population of people with prior coronary artery bypass graft surgery (CABG) who present with non-ST elevation myocardial infarction (NSTEMI) is growing and pose a diagnostic and therapeutic challenge in interventional cardiology.

- Application of Global Registry of Acute Cardiac Events (GRACE) score in this very high risk population is difficult as it has been under represented in major trials.

- The opportunity to intervene in this group is often low and an initial medical management may be reasonable in carefully selected patients, particularly in the absence of ongoing symptoms, ECG changes, or very high GRACE scores.

advances in coronary artery bypass graft surgery (CABG) and percutaneous coronary intervention (PCI) techniques and equipment, risk of adverse cardiac outcomes remain high as compared with normal population. ${ }^{2}{ }^{2}$ Current guidelines support an early invasive strategy for CAD including high-risk unstable angina pectoris (UAP), non-ST elevation myocardial infarction (NSTEMI) and ST-elevation myocardial infarction (STEMI). The best strategy in the subgroup of patients with prior CABG who present with NSTEMI however remains less well defined. This population, despite a growing number, has been either underrepresented or excluded in major trials ${ }^{3-6}$; and stronger evidence-based management strategies are required to improve their clinical outcomes. This retrospective observational study compares the characteristics, therapeutic interventions and outcomes of patients with prior CABG presenting with NSTEMI. 


\section{METHODS}

Available electronic records of patients who presented to Northern Health (Melbourne, Australia) during 20072012 were screened. All patients who had a history of CABG and a discharge diagnosis of NSTEMI were analysed. Standard definition of NSTEMI was used. ${ }^{7}$ The patients were divided into a coronary angiography group and a medically managed group if they did not undergo angiography during the index admission or within 2 weeks of discharge. The coronary angiography group was further categorised on the basis of requiring percutaneous intervention. Characteristics and outcomes were compared between patients who underwent coronary angiography, PCI, and who were treated medically. Global Registry of Acute Cardiac Events (GRACE) risk score, which is a validated predictor of inhospital mortality, was calculated based on age, heart rate, systolic blood pressure, Killip class, cardiac arrest, ECG changes, serum creatinine level and cardiac biomarker status of each patient on presentation. ECG changes were defined as new ST segment depression or transient elevation $\geq 1 \mathrm{~mm}^{6}$

Two-sample $\mathrm{t}$ test was used to compare continuous data and equal variances were assumed. $c^{2}$ And Fisher's exact tests were performed for categorical data. A twotailed $p$ values of $<0.05$ was considered statistically significant. Factors found significant on univariate analysis were adjusted on multivariate analysis to look for independent associations.

\begin{tabular}{|c|c|c|c|}
\hline & $\begin{array}{l}\text { Coronary } \\
\text { angiogram not } \\
\text { performed } \\
(n=79)\end{array}$ & $\begin{array}{l}\text { Coronary } \\
\text { angiogram } \\
\text { performed } \\
(n=38)\end{array}$ & $\begin{array}{l}p \\
\text { Value }\end{array}$ \\
\hline Age & $74 \pm 10$ & $70 \pm 8$ & 0.05 \\
\hline Males & $62 \%$ & $74 \%$ & 0.2 \\
\hline Length of stay & $5.6 \pm 4.2$ & $8.1 \pm 6.4$ & 0.01 \\
\hline $\begin{array}{l}\text { Troponin I } \\
\text { levels }\end{array}$ & $2.0 \pm 4.6$ & $4.7 \pm 10.6$ & 0.06 \\
\hline $\begin{array}{l}\text { New ECG } \\
\text { changes }\end{array}$ & $30 \%$ & $57 \%$ & 0.01 \\
\hline $\begin{array}{l}\text { Recurrent } \\
\text { chest pain }\end{array}$ & $27 \%$ & $49 \%$ & 0.02 \\
\hline Diabetes & $53 \%$ & $45 \%$ & 0.4 \\
\hline Hypertension & $75 \%$ & $87 \%$ & 0.1 \\
\hline $\begin{array}{l}\text { Months since } \\
\text { CABG }\end{array}$ & $140 \pm 103$ & $148 \pm 84$ & 0.7 \\
\hline $\begin{array}{l}\text { Number of } \\
\text { grafts }\end{array}$ & $3.1 \pm 1$ & $2.8 \pm 0.9$ & 0.1 \\
\hline $\begin{array}{l}\text { Ejection } \\
\text { fraction }\end{array}$ & $52 \pm 16$ & $49 \pm 13$ & 0.4 \\
\hline Creatinine & $114 \pm 56$ & $111 \pm 49$ & 0.8 \\
\hline Haemoglobin & $123 \pm 22$ & $131 \pm 16$ & 0.05 \\
\hline Albumin & $35 \pm 4$ & $37 \pm 4$ & 0.02 \\
\hline GRACE score & $150 \pm 29$ & $158 \pm 36$ & 0.2 \\
\hline
\end{tabular}

\section{RESULTS}

A total of 117 patients were analysed, mean age $73 \pm 10$, and $26.5 \% \geq 80$ years old. Of these, 79 patients were managed medically while 38 underwent angiography during the index admission or within 2 weeks of discharge, of which only 11 (9.5\% of total patients) received PCI. Baseline and angiographic characteristics of these patients are presented in tables 1 and 2, respectively. A subsequent angiography after 2 weeks of discharge but within next 1 year was performed in 12 patients (mean time period of $11.08 \pm 7.5$ weeks). Two patients required redo surgery (one with severe vein graft to the left anterior descending artery (LAD) disease and second with non-grafted LAD disease). Patients treated only medically (no angiogram) were older as compared with who received an early angiography $(74 \pm 10$ vs $70 \pm 8 ; \mathrm{p}=0.05)$. Troponin levels were higher in the group that underwent coronary angiography (whether or not required PCI) as compared with patients who did not undergo angiography, but did not reach statistical significance $(4.7 \pm 10.6$ vs $2 \pm 4.6 ; \mathrm{p}=0.06)$. Furthermore, the medically managed group (as compared with patients who had underwent an early angiogram) had lower albumin ( $35 \pm 4$ vs $37 \pm 4 ; p=0.02)$ and lower haemoglobin levels $(123 \pm 22$ vs $131 \pm 16$; $\mathrm{p}=0.05)$. Most of the patients $(63 \%)$ who had angiogram but no revascularisation did not have any definitive culprit lesion identified. The majority of patients (64\%) who received revascularisation had the culprit lesion in an ungrafted vessel (table 2).

Multinomial logistic regression was performed on variables including age, ECG changes, recurrent chest pain, troponin, haemoglobin and albumin levels on admission, to look for independent predictors for angiography and PCI. ECG changes were the only independent predictor for early angiography (OR $0.4,95 \%$ CI 0.15 to 0.99 ; $\mathrm{p}=0.05$ ). Recurrent chest pain, defined as two or more episodes of chest pains during inpatient stay, predicted PCI on multivariate analysis (OR $0.2,95 \%$ CI 0.05 to $0.97 ; p=0.05)$. The PCI group had higher GRACE score than the rest of the patients $(176 \pm 29$ vs $150 \pm 31 ; p=0.01)$.

Medical treatment was similar across the groups except that the patients who were revascularised were significantly more likely to receive ACE inhibitors or angiotensin receptor blockers (table 3). No significant difference was found in readmission rates, morbidity (defined as UAP, NSTEMI, STEMI or combination) or mortality at 12 months between the groups who underwent angiography, PCI, or treated medically on univariate and multivariate analysis (table 4). Two patients in the PCI group died, both after 2 weeks of hospital discharge (4 and 9 months). A total of 12 patients died in the group who did not undergo PCI, of which 3 were inhospital deaths, that is, during the index admission (2 cardiac and 1 non-cardiac deaths). An increased length of stay in hospital was noted in the group who underwent a coronary angiogram whether or not required PCI $(8.1 \pm 6.4$ vs $5.6 \pm 4.2 ; \mathrm{p}=0.01)$. 
Table 2 Angiographic characteristics

\begin{tabular}{lllc}
\hline & $\begin{array}{l}\text { No revascularisation } \\
(\mathbf{n}=\mathbf{2 7})\end{array}$ & $\begin{array}{l}\text { Percutaneous coronary intervention } \\
(\mathbf{n = 1 1 )}\end{array}$ & $\mathbf{p}$ Value \\
\hline Culprit lesion & & 0 & $<0.0001$ \\
$\quad$ Not identified & $17(63 \%)$ & $7(64 \%)$ & 0.005 \\
Ungrafted native vessel & $4(15 \%)$ & $3(27 \%)$ & 0.4 \\
Grafted native vessel & $4(15 \%)$ & $1(9 \%)$ & 1.0 \\
Vein graft & $2(7 \%)$ & 0 & Not applicable \\
Arterial graft & 0 & $0.18 \pm 0.4$ & 0.3 \\
Occluded grafts/severe disease & $(70 \%$ angiographic stenosis) & \\
Total & $0.41 \pm 0.7$ & 0 & 0.1 \\
Arterial & $0.22 \pm 0.5$ & $0.18 \pm 0.4$ & 0.9 \\
Venous & $0.19 \pm 0.4$ & & \\
\hline
\end{tabular}

\section{DISCUSSION}

This study represents the real-world data on a growing population of people with prior CABG who present with NSTEMI. We found that most of these patients did not undergo an early coronary angiogram, and a very small percentage was treated with percutaneous intervention. These were the patients with recurrent symptoms of chest pain or new ST changes on ECG, and had very high GRACE scores $(176 \pm 29)$. This group represents a very high-risk patient population regardless of any opportunity to intervene as evident by our mortality data. The GRACE registry used a cut-off score of 140 to denote high-risk patients; however, it is noted that only $14 \%$ patients of the NSTEMI arm had a history of $\mathrm{CABG}^{6}$ in the registry. The under-representation of this specific population with high mortality makes the interpretation and application of GRACE score to guide an early coronary angiography difficult. Furthermore, a history of CABG was the third biggest independent predictor of 'no reperfusion' (OR 2.28; CI 1.35 to 3.87) after heart failure and age, in patients presenting with acute coronary syndrome (ACS) ${ }^{8}$ A lower rate of angiography was also seen compared with "no prior CABG group', adjusted for age, gender and diagnosis at presentation (OR 0.64; CI 0.54 to 0.75).

Despite the advances in the treatment of $\mathrm{CAD}$, patients with prior CABG and ACS have a poor prognosis as compared with patients without prior CABG. Our study demonstrates no significant difference in clinical outcomes at 1 year between the initial medical management and early intervention groups. This includes all-cause death, ACS and stable symptoms. Length of stay was longer in the patients who had an early coronary angiography performed which may be due to angiography-associated delays or may represent a more unstable group of patients requiring invasive management strategy. Somewhat similar results have been reported by the Acute Catheterization and Urgent Intervention Triage Strategy (ACUITY) trial, ${ }^{9}$ in which adjusted 30-day and 1-year rates of major adverse cardiac events were increased in patients treated with revascularisation rather than medically. This cohort included patients with prior CABG presenting with ACS including UAP. All patients underwent diagnostic coronary angiography and in the medically treated patients, revascularisation was declined due to either the physician's or patient's preference, lesion anatomy, absence of significant lesion or due to comorbidities. Similarly, 6-month mortality of patients with ACS with prior CABG in the GRACE was lower in patients revascularised versus those treated medically on univariate but not on multivariable analysis. Data indicated that an invasive approach within $48 \mathrm{~h}$ did not improve inhospital or 6-month death, rehospitalisation for heart disease or non-fatal

Table 3 Medication at discharge after the index admission

\begin{tabular}{lccl}
\hline & $\begin{array}{l}\text { No revascularisation } \\
(\mathbf{n = 1 0 6})\end{array}$ & $\begin{array}{l}\text { Percutaneous coronary } \\
\text { intervention }(\mathbf{n = 1 1 )}\end{array}$ & p Value \\
\hline Aspirin & $106(100 \%)$ & $11(100 \%)$ & 1 \\
Clopidogrel/ticagrelor/prasugrel & $100(94 \%)$ & $11(100 \%)$ & 0.4 \\
ACE inhibitors/angiotensin receptor blockers & $55(52 \%)$ & $11(100 \%)$ & 0.002 \\
B-Blockers & $97(91.5 \%)$ & $9(82 \%)$ & 0.3 \\
Calcium channel blockers & $80(75 \%)$ & $8(73 \%)$ & 0.8 \\
Nitrates & $63(59 \%)$ & $7(64 \%)$ & 0.8 \\
Nicorandil & $39(37 \%)$ & $1(9 \%)$ & 0.06 \\
Statins & $102(96 \%)$ & $11(100 \%)$ & 0.5 \\
\hline
\end{tabular}


Table 4 Outcomes at 12 months on multivariate analysis using logistic regression

\begin{tabular}{llll}
\hline & $\begin{array}{l}\text { No } \\
\text { revascularisation }\end{array}$ & $\begin{array}{l}\text { Percutaneous } \\
\text { coronary } \\
\text { intervention }\end{array}$ & $\begin{array}{l}\mathbf{p} \\
\text { Value }\end{array}$ \\
\hline Readmissions & $1.56 \pm 2.5$ & $1.55 \pm 2.5$ & 0.96 \\
Deaths & $12 \%$ & $18 \%$ & 0.63 \\
STEMI & $1 \%$ & $0 \%$ & 1.0 \\
NSTEMI & $22 \%$ & $18 \%$ & 0.81 \\
Stable angina & $16 \%$ & $18 \%$ & 0.98 \\
Asymptomatic & $49 \%$ & $45.5 \%$ & 0.84 \\
\hline STEMI, ST elevation myocardial infarction; NSTEMI, non-ST \\
elevation myocardial infarction.
\end{tabular}

reinfarction. Conversely, it was associated with increased risk of major bleeding, including haemorrhagic stroke. A large Swedish registry on the other hand, involving 10469 patients with previous CABG, showed 1-year adjusted mortality was $50 \%$ lower with revascularisation compared with medical management. ${ }^{10}$ The study included NSTEMI and UAP, and excluded patients $>80$ years. In all, $33 \%$ of NSTEMI while $50 \%$ of the UAP subgroups received revascularisation. Interestingly, revascularisation in UAP was associated with an increased mortality as compared with no revascularisation.

Overall, there is conflicting data and no concrete evidence exists for any single strategy over the other in this specific population. The risk-benefit ratio may differ in this subset and perhaps an improved selection of patients who would benefit the most from invasive management using initial non-invasive means may prove useful. Our study is limited by its small number and a retrospective observational design and a significant selection bias cannot be removed. It does not have the power to draw any definitive conclusions; however, it does raise questions about the best management strategy in this particular cohort, and highlights the vacuum in evidence. A randomised trial may be able to answer this question in future.

\section{CONCLUSION}

The opportunity to intervene in patients with prior CABG presenting with NSTEMI is often low. Initial medical management may be a reasonable option in carefully selected patients particularly in the absence of ongoing symptoms, ECG changes or very high GRACE scores. Further studies are required to evaluate the safety of initial non-invasive strategies in managing this population.

Funding This research received no specific grant from any funding agency in the public, commercial or not-for-profit sectors.

Competing interests None.

Provenance and peer review Not commissioned; externally peer reviewed.

Data sharing statement No additional data are available.

Open Access This is an Open Access article distributed in accordance with the Creative Commons Attribution Non Commercial (CC BY-NC 3.0) license, which permits others to distribute, remix, adapt, build upon this work noncommercially, and license their derivative works on different terms, provided the original work is properly cited and the use is non-commercial. See: http:// creativecommons.org/licenses/by-nc/3.0/

\section{REFERENCES}

1. Fitzgibbon GM, Kafka HP, Leach AJ, et al. Coronary bypass graft fate and patient outcome: angiographic follow-up of 5,065 grafts related to survival and reoperation in 1,388 patients during 25 years. J Am Coll Cardiol 1996;28:616-26.

2. Kim MS, Wang TY, Ou FS, et al. Association of prior coronary artery bypass graft surgery with quality of care of patients with non-ST-segment elevation myocardial infarction: a report from the National Cardiovascular Data Registry Acute Coronary Treatment and Intervention Outcomes Network Registry-Get With the Guidelines. Am Heart J 2010;160:951-7.

3. Invasive compared with non-invasive treatment in unstable coronary-artery disease: FRISC II prospective randomised multicentre study. FRagmin and Fast Revascularisation during InStability in Coronary artery disease Investigators. Lancet 1999;354:708-15.

4. Cannon CP, Weintraub WS, Demopoulos LA, et al. Comparison of early invasive and conservative strategies in patients with unstable coronary syndromes treated with the glycoprotein Ilb/IIla inhibitor tirofiban. N Engl J Med 2001;344:1879-87.

5. Fox KA, Poole-Wilson PA, Henderson RA, et al. Interventional versus conservative treatment for patients with unstable angina or non-ST-elevation myocardial infarction: the British Heart Foundation RITA 3 randomised trial. Randomized Intervention Trial of unstable angina. Lancet 2002;360:743-51.

6. Fox KA, Goodman SG, Klein W, et al. Management of acute coronary syndromes. Variations in practice and outcome; findings from the Global Registry of Acute Coronary Events (GRACE). Eur Heart J 2002;23:1177-89.

7. Thygesen K, Alpert JS, Jaffe AS, et al. Third universal definition of myocardial infarction. Circulation 2012;126:2020-35.

8. Eagle KA, Goodman SG, Avezum A, et al. Practice variation and missed opportunities for reperfusion in ST-segment-elevation myocardial infarction: findings from the Global Registry of Acute Coronary Events (GRACE). Lancet 2002;359:373-7.

9. Nikolsky E, McLaurin BT, Cox DA, et al. Outcomes of patients with prior coronary artery bypass grafting and acute coronary syndromes: analysis from the ACUITY (Acute Catheterization and Urgent Intervention Triage Strategy) trial. JACC Cardiovasc Interv 2012;5:919-26.

10. Held C, Tornvall P, Stenestrand U. Effects of revascularization within 14 days of hospital admission due to acute coronary syndrome on 1 -year mortality in patients with previous coronary artery bypass graft surgery. Eur Heart J 2007;28:316-25. 